\title{
Agenesis of the right lung: an unusual presentation
}

\author{
W. PALLIE, S. M. A. ALHADY, AND OMAR B IN D IN \\ From the Department of Anatomy, Faculty of Medicine, University of Malaya, and \\ the Departments of Surgery and Radiology, General Hospital, Kuala Lumpur
}

A case of agenesis or aplasia of the right lung, in a cyanosed neonate, exceptionally associated with a 'vascular ring' abnormality produced by a right aortic arch, an aberrant left subclavian artery, and a patent ductus arteriosus, is reported. The presence of an abnormal lobe of the liver, projecting together with small gut and a subhepatic caecum into the right hemithorax, caused mediastinal displacement to the left side and produced the illusion of a diaphragmatic hernia, thereby obscuring the correct preoperative diagnosis.

Agenesis or aplasia (Schneider, 1912) of a lung is an infrequent anomaly, particularly so if degrees of hypoplasia where some recognizable lung tissue is present (Rosenberg, 1962 ; Levine, Coryllos, and Goddard, 1966) are excluded. The reviews and reports of this condition in the literature (Hurwitz and Stephens, 1937 ; Killingsworth and Hibbs, 1939 ; Valle and Graham, 1944 ; Burger, 1947 ; Wexels, 1951 ; Oyamada, Gasul, and Holinger, 1953 ; Hochberg and Naclerio, 1955 ; Valle, 1955 ; Brescia, Amerman, and Sharma, 1960) do not total more than a hundred cases in the newborn.

The case reported here, in a 2-day-old male child with right lung agenesis, is further unusual on account of its misleading clinical and radiological presentation and the related exceptional anomalies.

\section{CASE REPORT}

An Indian male child weighing $6 \mathrm{lb} .13 \mathrm{oz}$. (3 kg.) was born on 26 July 1966 at 11.17 a.m. in the Maternity Hospital and transferred to the Paediatric Unit for observation on account of cyanosis. Oxygen was administered, and the next day the colour was better, the cry was good, and feeds were begun. On the following day the case report records 'no air entry right side of chest, stomach tube passed readily into stomach ; temperature normal'.

RADIOLOGICAL FINDINGS A postero-anterior radiograph of the chest (Fig. 1) showed marked displacement of the heart and mediastinum towards the left. The left hemidiaphragm was normal but the right hemidiaphragm was not visible, and the liver shadow

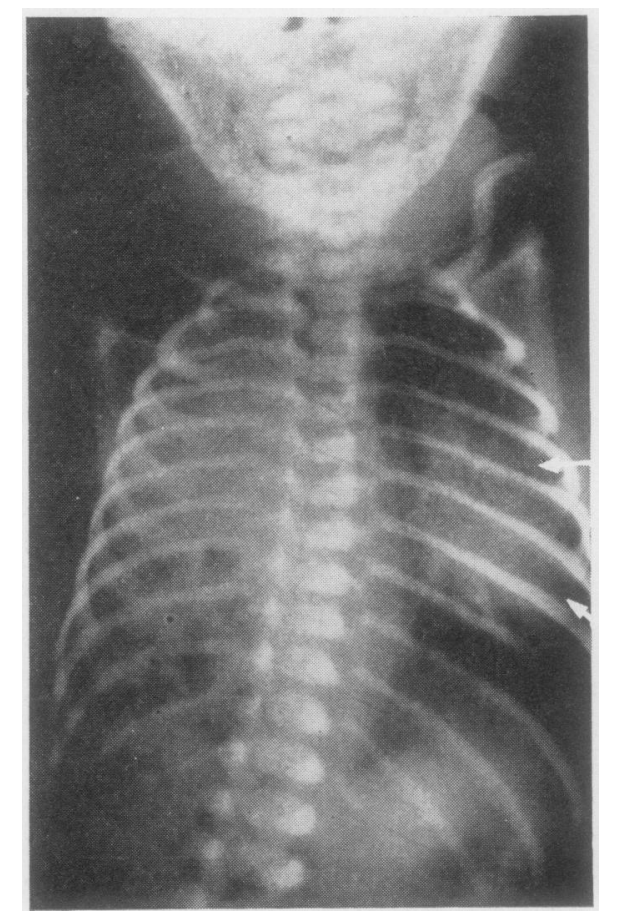

FIG. 1. The heart is dispiaced to the ieft (arrows), the $\stackrel{0}{0}$ gas-filled loops of bowel are seen in the right hemithorax $\stackrel{\widetilde{\Omega}}{\mathbb{D}}$ inferiorly while superiorly a dense mass is seen merging $\underset{\mathbb{D}}{ }$ with the central shadow descending to the level of the left diaphragm. This mass is later found to represent the liver and its abnormal lobe. 


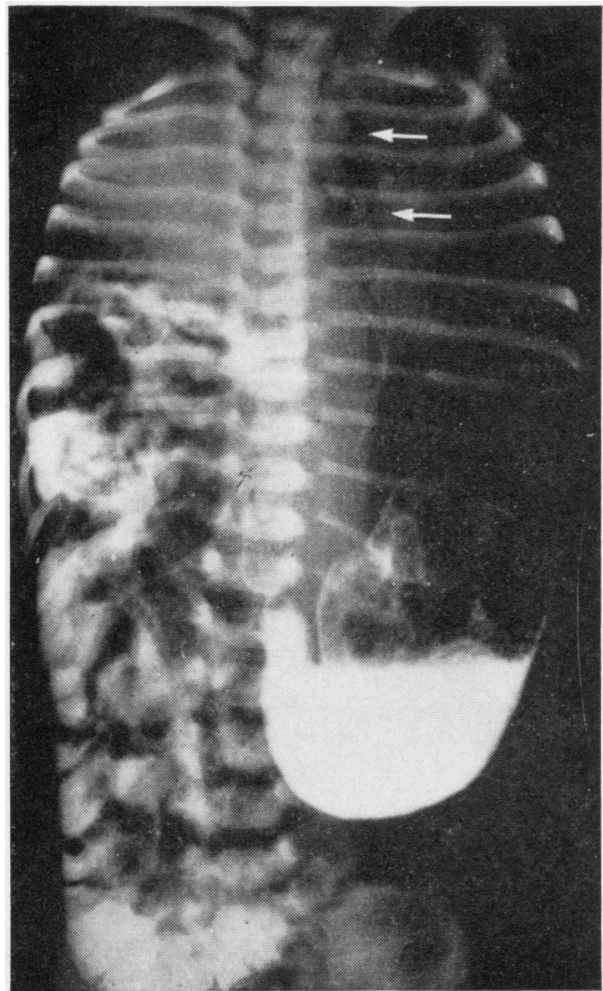

FIG. 2

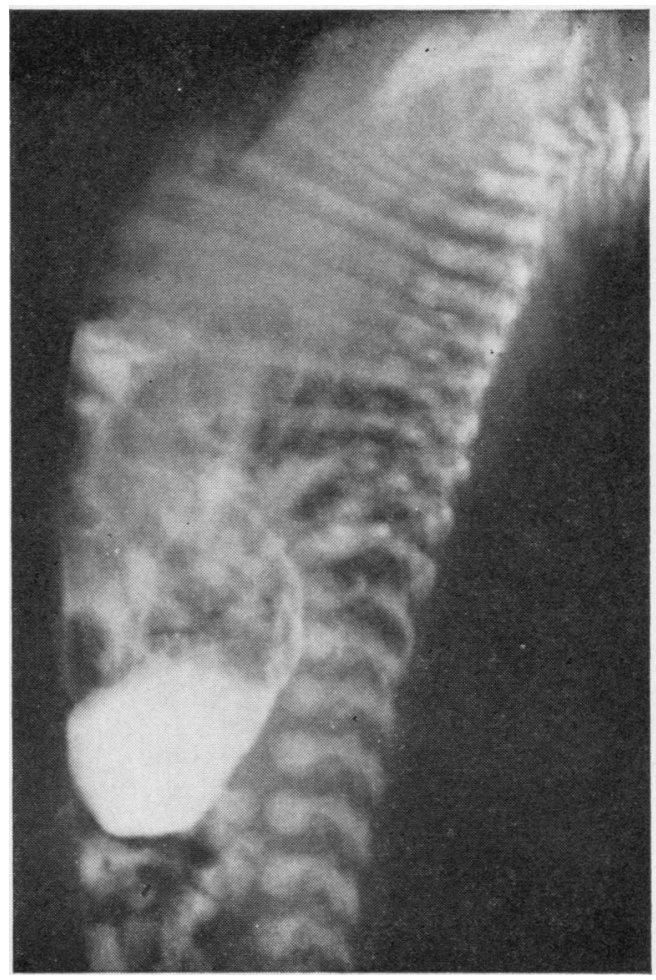

FIG. 3

FIG. 2. The loops of bowel are seen filled with Gastrografin. The shadow of the displaced trachea and the main bronchi are clearly seen (arrows). FIG. 3. Lateral view of the chest after Gastrografin swallow.

could not be seen in its normal position. In the right hemithorax there were cyst-like collections of air suggestive of gas-filled loops of intestine in the lower part, while a homogeneous dense mass occupied the upper part, and this appeared to be continuous with a central shadow reaching down to the level of the left hemidiaphragm. A right-sided diaphragmatic hernia was diagnosed. It was thought that the dense shadow seen could be produced by a herniated liver or compressed lung or an accumulation of pleural exudate or even a neuro-enteric cyst, although no abnormalities were seen on the spine.

A Gastrografin swallow was given and this outlined the ileal loops in the lower lateral and anterior aspects of the right hemithorax (Figs 2 and 3).

SURGICAL OPERATION Under endotracheal anaesthesia a right thoracotomy incision through the eighth interspace was made. On entering the pleural cavity the diaphragm was found to be arched high up into the thoracic cavity, and through it a solid firm mass, with some intestines in front, was palpable. The right lung was absent. The wound was closed in layers.

The child remained cyanosed and died the next day.
NECROPSY FINDINGS The oesophagus was normal and there was no tracheal communication. The trachea was normal ; it was slightly deviated to the left.

The left bronchus was normal. The right bronchus was $0.5 \mathrm{~cm}$. long and divided into two; it ended blindly against diaphragmatic connective tissue (Figs 4 and 5).

The liver was large and an abnormal lobe of conical shape, about $5 \mathrm{~cm}$. in length, projected into the right hemithorax ; it was domed over by the right hemidiaphragm, which fitted snugly over the front of the liver lobe (Figs 6 and 7). The bulge of liver covered over by diaphragm reduced the size of the right pleural cavity, which was narrowed to a crevice, crescentic in outline (Fig. 7).

The right hemidiaphragm was well formed and complete - it was continuous on the left into the central tendon and the left half of the diaphragm.

The heart and pericardium were normal; but the heart lay transversely and was displaced to the left (Fig. 6). Its internal structure was normal. There was no septal defect, dextraposition or 'overriding' of the aorta or pulmonary artery. The right pulmonary veins were absent. 


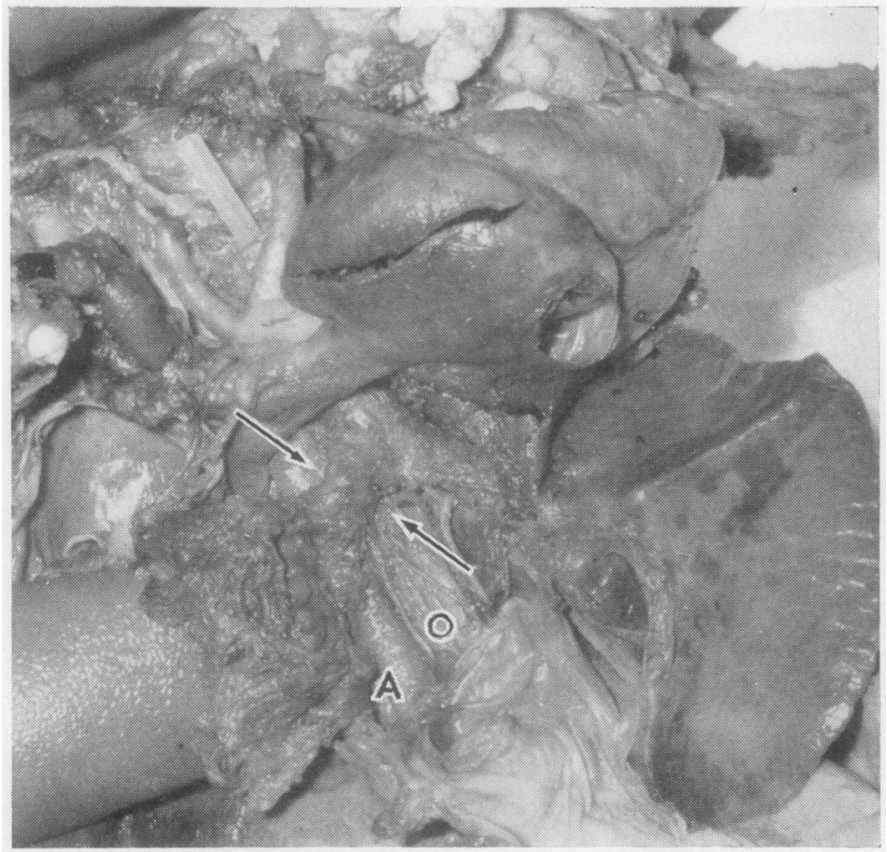

FIG. 4. The tracheal division is seen. The short bifurcated right bronchus (arrows) ends blindly against diaphragmatic tissue. The descending aorta $(A)$ and the oesophagus $(O)$ with its nerve plexus are visible below. The absence of right pulmonary veins is evident.

FIG. 4

FIG. 5. Dissected specimen showing normal left lung and right bronchial stump ending in diaphragmatic connective tissue.

FIG. 6. The appearance in situ on removal of the anterior chest wall is seen. The right hemidiaphragm (D) is domed high into the right chest by the abnormal iiver lobe $(L)$ separated from the main mass of liver by a deep sulcus. The heart $(H)$ is pushed to the left and lies transversely.

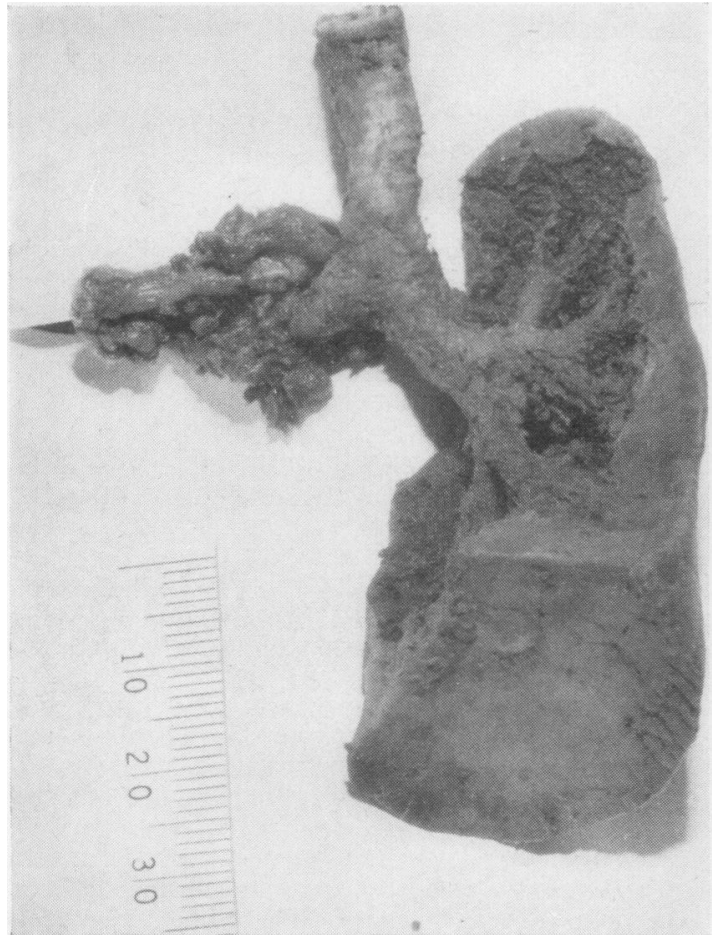

FIG. 5

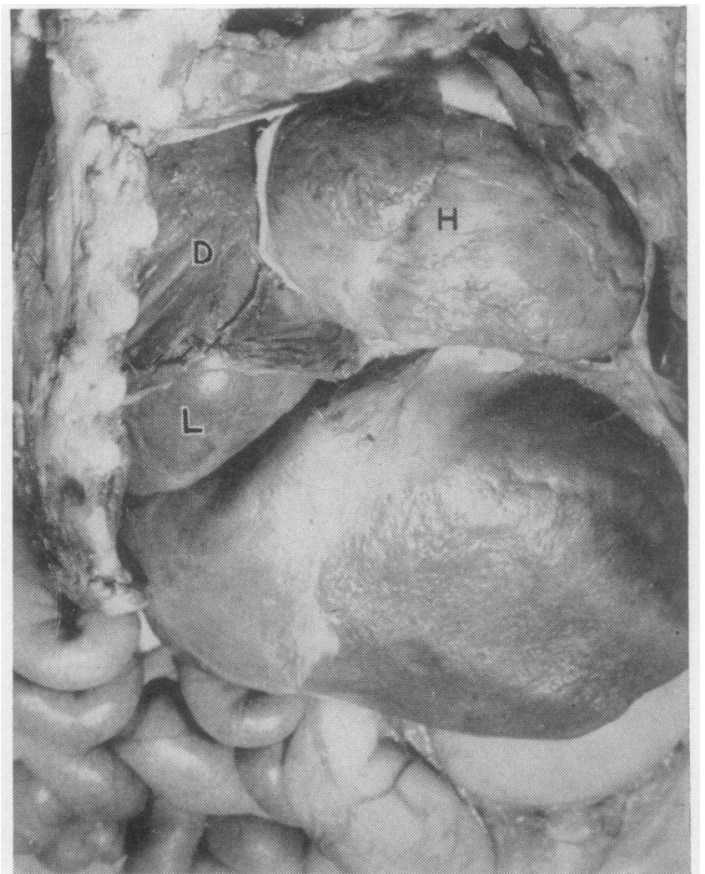

FIG. 6 


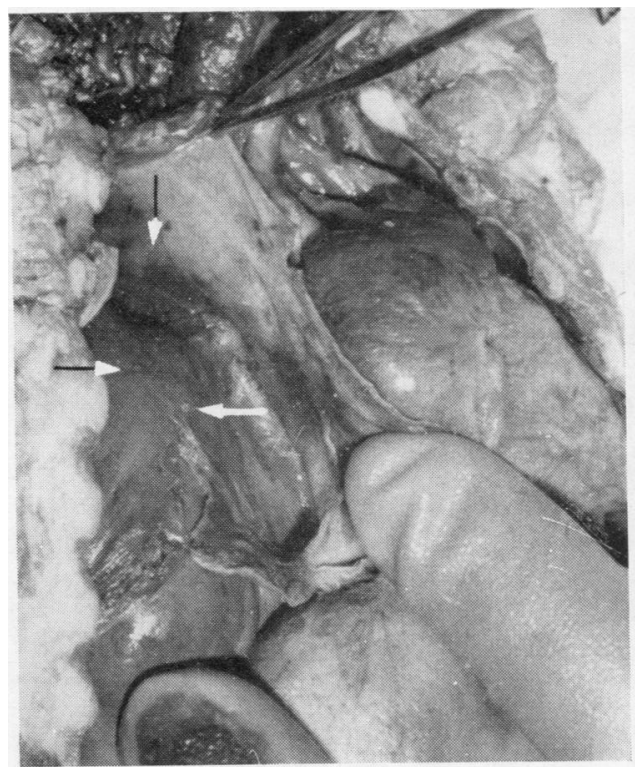

FIG. 7. The right pleural cavity (arrows) is exposed by retraction of the right hemidiaphragm and liver. There is no lung or bulge in the right mediastinal pleura.

FIG. 8. The abnormal liver lobe $(L)$ is shown after removal of the diaphragm over it and retraction of the intestines downwards. The subhepatic caecum and vermiform appendix are seen above the 'empty' right iliac fossa.

FIG. 7

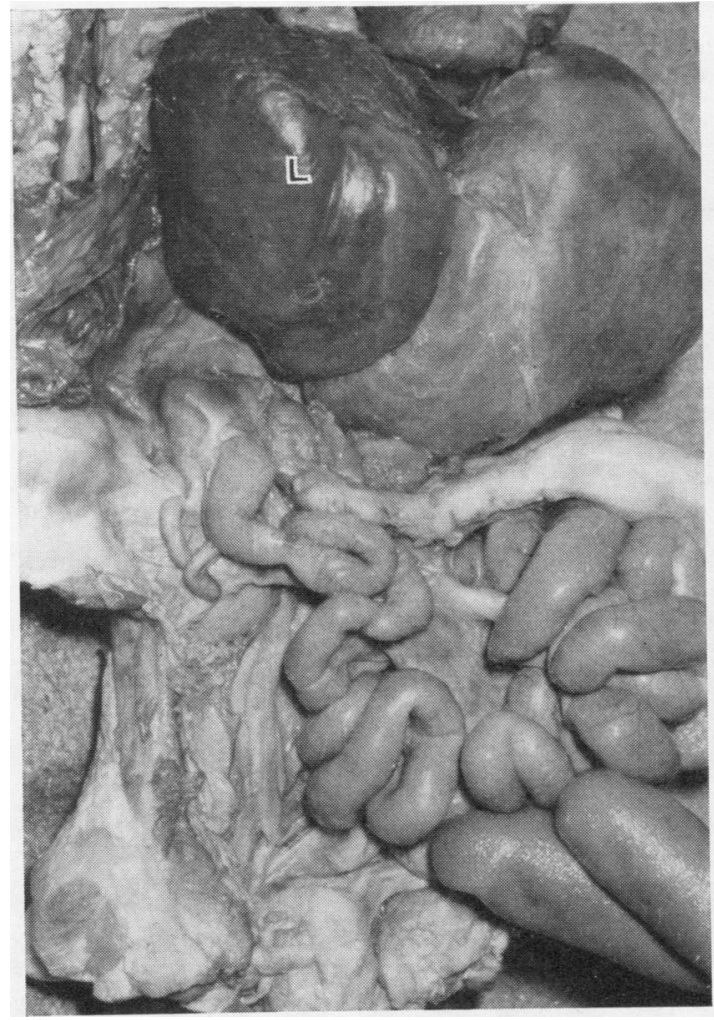

FIG. 8

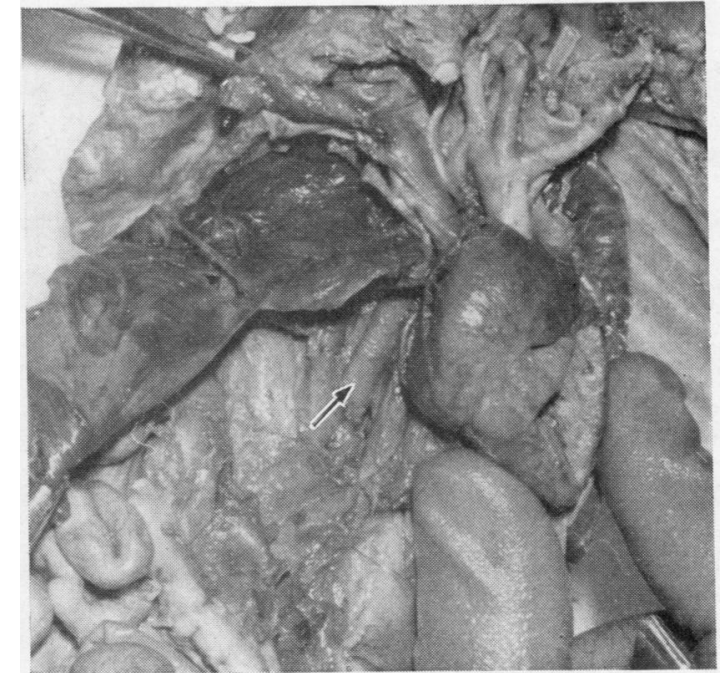

FIG. 9. Liver removed to expose right aortic arch continuing down as descending aorta (arrow) to the right of the oesophagus. The arch, giving off the left common carotid, right common carotid, and right subclavian arteries, in that order, is seen with the right vagus nerve lying on it. 


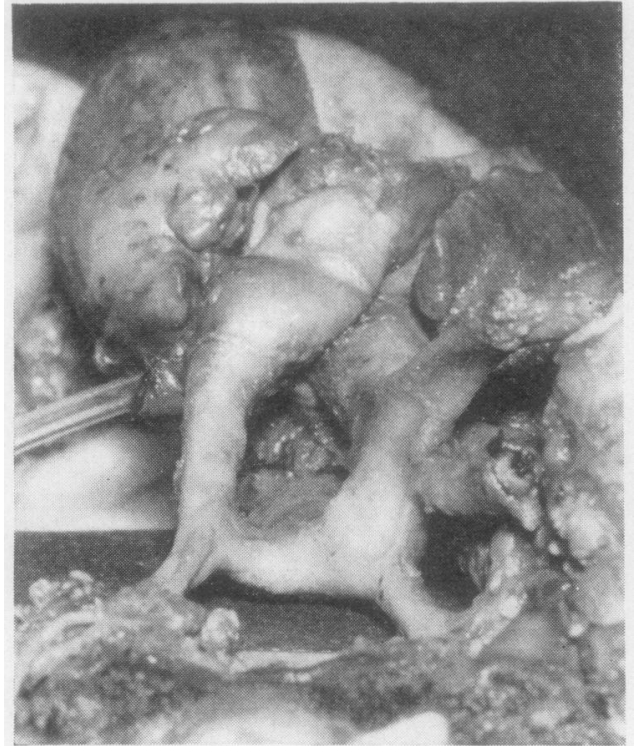

FIG. 10. The vascuar ring seen from above, with the oesophagus and trachea removed from within it. A polythene tube lies in the left pulmonary artery.

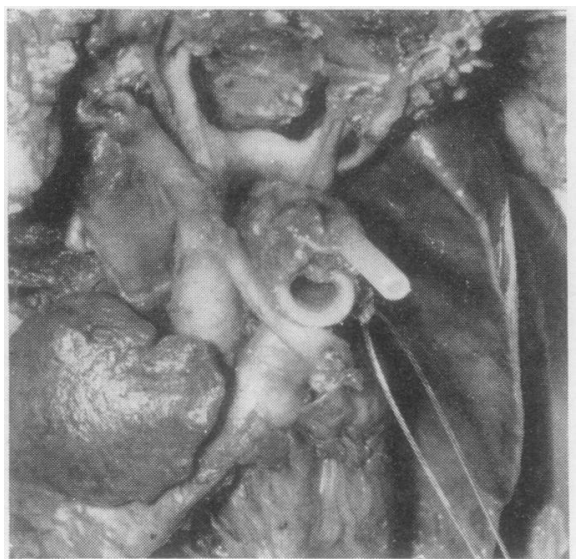

FIG. 11. A view of the vascular ring to show the retrooesophageal segment in situ. A polythene tube lies in the oesophagus.

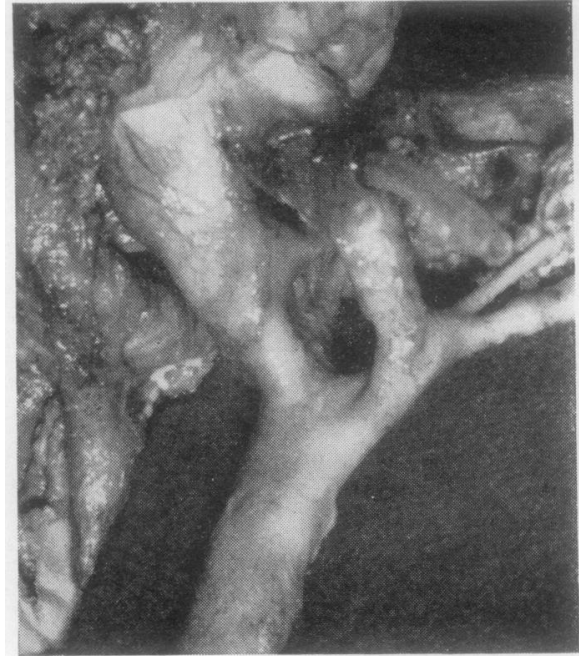

FIG. 12. The vascular ring seen from below to show continuity with the descending aorta.

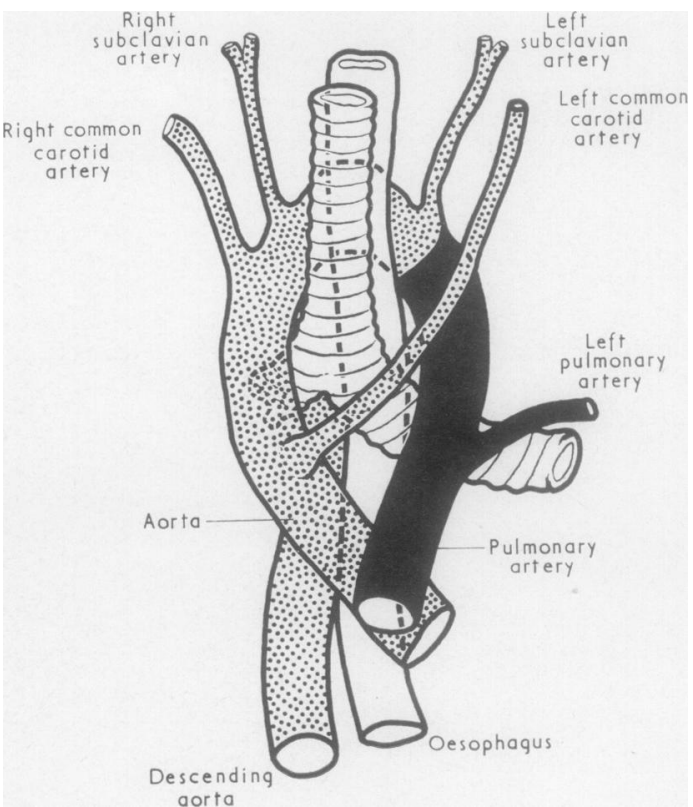

FIG. 13. A diagram to illustrate the nature of the vascular anomaly. The segment distal to the left pulmonary artery represents the left ductus arteriosus, merging with the $\mathbb{Q}$ left aortic arch. The latter gives off the left subclavian artery. 
The right pleural cavity was compressed and crescentic in shape; it was otherwise normal. The mediastinal pleura on the right side was smooth and unbulged; it covered the normal pericardium (Fig. 7).

The abdomen contained a subhepatic caecum with small intestine adjacent to it (Fig. 8). The kidneys were normal: but the middle segment of the right ureter was dilated. There was no hydronephrosis.

A right aortic arch was present together with a 'vascular ring' vessel which passed behind the oesophagus and trachea, and which gave origin to the left subclavian artery and connected with the pulmonary trunk (Figs 9 to 13). The latter gave rise to a left pulmonary artery only. The right pulmonary vessels were absent.

\section{DISCUSSION}

In agenesis of the lung in the neonate, the classical signs in the chest (Hochberg and Naclerio, 1955) are an elevated diaphragm and mediastinal, tracheal, and cardiac shift to the defective side. In right lung agenesis an illusion of dextrocardia may occur (Brünner and Nissen, 1963). The possibility that mediastinal flutter may occur has been suggested (Levine et al., 1966). The radiological appearance to be expected in right lung agenesis includes a homogeneous opacity in the right chest due to fluid, fatty tissue, a persistent thymus, or a shifted mediastinum (Brünner and Nissen, 1963).

In the case reported here, displacement was prevented by the abnormal liver lobe, which occupied the right hemithorax, pushing up the diaphragm before it. In fact, this feature together with the upward protrusion of intestine beneath a very elevated right diaphragm presented the illusion of a diaphragmatic hernia (Figs 1 and 2) for which this child was operated on. The space occupied by these structures was inadequate and resulted in displacement of the heart to the left (Figs 1 and 2).

Right-sided agenesis of the lung is reported to have about twice as poor a prognosis as that of left-sided agenesis (Oyamada et al., 1953). The greater mediastinal displacement in right-sided agenesis (Brünner and Nissen, 1963) and the kinking or compression of the great vessels and large bronchi produced thereby (Schaffer, 1965) have been suggested as reasons for this higher mortality rate. Fifty per cent of the patients die in the first five years of life, mainly from a reduced resistance to respiratory tract infection or an associated congenital anomaly (Rosenberg, 1962; Schaffer, 1965).

The incidence of congenital anomalies is given as $50 \%$ (Wexels, 1951) to $60 \%$ (Schaffer and Rider, 1957), and these have been listed (Hochberg and Naclerio, 1955 ; Oyamada et al., 1953). In a series of 120 cases, $37.5 \%$ (Valle, 1955) are recorded as cardiovascular anomalies. Patent ductus arteriosus (Altmann, 1928 ; Gruber, 1870), interventricular septal defect by itself (Hein, 1837 ; Field, 1946) or associated with dextrocardia (Botár and Orts Llorca, 1932), and coarctation of the aorta (Thomas and Boyden, 1952) have been reported.

There is no record of a vascular aortic ring occurring in cases of agenesis of the lung. Though such a ring occurred in the present case, the classical signs of opisthotonic position, noisy and laboured respiration aggravated during feeding, or the radiographic signs of oesophageal and tracheal compression associated with this abnormality (Levine et al., 1966) were not prominent enough to be observed or looked for.

This anomaly approximated to the 'right aortic arch, aberrant subclavian artery, and left ductus arteriosus' described and categorized as subgroups III $B$ I in the classification of vascular rings and aortic arch malformations analysed by Stewart, Kincaid, and Edwards (1964). However, in the case reported here, the patent left ductus was so wide that it appeared smoothly incorporated, without constriction, with the vascular ring vessel (Fig. 10). Thus, the external appearance on the left side was of a segment of the 'ring vessel' continuous with the pulmonary trunk and giving rise to the left pulmonary artery and (aberrant) left subclavian artery as well. There were no right pulmonary arteries or veins. The absence of right pulmonary vessels does not contradict the suggestion that malformation of the pulmonary circulation is the primary defect in this anomaly (Ellis, 1917).

This case presented with cyanosis, though in the absence of a lung this sign is not present (Avery, 1964). The cyanosis in this instance is explicable on the basis of the vascular anomaly recorded here, the offending vessel being the dilated left ductus arteriosus segment, permitting venous blood to enter the systemic circulation via the anomalous 'ring vessel'.

The left lung in this instance did not show any abnormality of bronchial vascular pattern (Fig. 5), contrary to previous reports in such cases (Brünner and Nissen, 1963) which have recorded supernumerary lobes, atypical bronchial branching, and retrobronchial pulmonary artery (Thomas and Boyden, 1952).

The protuberant growth of the right liver lobe filling the right side of the thorax is an exceptional finding. The lung buds, detectable as an outgrowth 
of the tracheal primodium in the $3-\mathrm{mm}$. embryo (Baxter, 1953), and the hepatic diverticulum, appearing at the same time in the 22-day or 19somite embryo (Elias, 1955), grow rapidly thereafter. The anomaly of lung agenesis is an interference at the end of the first month of development (Thomas and Boyden, 1952; Valle, 1955). The rapid growth of the liver in the second and third months, invading and perhaps even being added to by mesenchymal cells of the septum transversum (Du Bois, 1963 ; Elias, 1955), makes it evident that this organ filled in the void left by right lung agenesis, thereby preventing the mediastinal displacement that otherwise might have occurred.

The literature records only three cases of agenesis reporting intestinal anomalies (Brescia et al., 1960). The high (subhepatic) caecum in this case is a minor anomaly. The small intestines projected high into the thorax, though in a subdiaphragmatic position. The radiological appearances (Figs 1 and 2) gave the illusion of a compressed right lung (actually the shadow of the abnormal liver lobe), herniated gut in the right hemithorax, and mediastinal shift to the left, and were diagnostically misleading in this instance.

The authors wish to acknowledge the assistance given by Mr. Zainal Abidin bin Hussein and Mr. Mah Chai Soon, of the Central Medical Illustration Department, University of Malaya, with photography and the diagram drawing respectively.

\section{REFERENCES}

Altmann, F. (1928). Zur Kenntnis der Lungenhypoplasien. Z. Anat. Entwickl.-Gesch., 88, 500.

Avery, M. E. (1964). The Lung and its Disorders in the Newborn Infant. Saunders, Philadelphia and London.

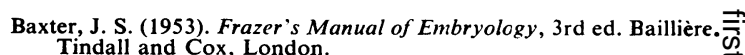

Botár, J., and Orts Llorca, F. (1932). Les Anomalies du poumon parO défaut. Absence partielle du poumon droit chez un nouveau-né humain. Ann. anat. path., 9, 820.

Brescia, M. A., Amerman, E. E., and Sharma, K. K. (1960). Agenesis of the left lung; case report. Arch. Pediat., 77, 485 .

Brünner, S., and Nissen, E. (1963). Agenesis of the lung. Amer. Rev. resp. Dis., 87, 103.

Burger, R. A. (1947). Agenesis of the lung, with a review of the literature. Amer. J. Dis. Child., 73, 481.

Du Bois, A. M. (1963). In The Liver. Ed. Rouiller, Vol. 1, pp. 1-39, $\vec{\ominus}$ Academic Press, New York.

Elias, H. (1955). Origin and early development of the liver in various $\vec{\omega}$ vertebrates. Acta hepat. (Hamburg), 3, 1.

Ellis, A. G. (1917). Congenital absence of lung. Amer. J. med. Sci., 154, 33.

Field, C. E. (1946). Pulmonary agenesis and hypoplasia. Arch. Dis. Childh., 21, 61 .

Gruber, W. (1870). Cited by Oyamada et al. (1953), loc. cit.

Hein (1837). Wschr. ges. Heilk. Berl., p. 536. Cited by Ellis, A. G. (1917), loc. cit.

Hochberg, L. A., and Naclerio, E. A. (1955). Congenital pulmonary agenesis. Dis. Chest, 28, 275.

Hurwitz, S., and Stephens, H. B. (1937). Agenesis of the lung. A review of the literature and report of a case. Amer. J. med. Sci., 193,81 .

Killingsworth, W. P., and Hibbs, W. G. (1939). Agenesis of the lung. Review of the literature and report of a case. Amer. J. Dis. Child., 58, 571.

Levine, M., Coryllos, E., and Goddard, R. F. (1966). Congenital oै pulmonary anomalies and related thoracic conditions. Dis. Chest, . 49, 441 .

Oyamada, A., Gasul, B. M., and Holinger, P. H. (1953). Agenesis of the lung. Amer. J. Dis. Child., 85, 182.

Rosenberg, D. M. L. (1962). Pulmonary agenesis. Dis. Chest, 42, 68.

Schaffer, A. J. (1965). Diseases of the Newborn, 2nd ed., p. 144. Saunders, Philadelphia and London.

- and Rider, R. V. (1957). A note on the prognosis of pulmonary $\overparen{D}$ agenesis and hypoplasia according to the side affected. $J$. thorac. Surg., 33, 379.

Schneider, P. (1912). Quoted in E. Schwalbe, Die Morphologie der Missbildungen des Menschen und der Tiere, Vol. 3. Fischer, Jena.

Stewart, J. R., Kincaid, O. W., and Edwards, J. E. (1964). An Atlas of Vascular Rings and Related Malformations of the Aortic Arch System. Thomas, Springfield, Illinois.

Thomas, L. B., and Boyden, E. A. (1952). Agenesis of the right lung: report of three cases. Surgery, 31, 429.

Valle, A. R. (1955). Agenesis of the lung. Amer. J. Surg., 89, 90. and Graham, E. A. (1944). Agenesis of the lung. J. thorac. Surg., 13, 345.

Wexels, P. (1951). Agenesis of the lung. Thorax, 6, 171. 